\title{
Commentary \\ How Much of CAM Is Based on Research Evidence?
}

\author{
Edzard Ernst \\ Complementary Medicine, Peninsula Medical School, Universities of Exeter and Plymouth, Exeter, UK \\ Correspondence should be addressed to Edzard Ernst, edzard.ernst@pms.ac.uk
}

Received 13 February 2009; Accepted 23 April 2009

Copyright (C 2011 Edzard Ernst. This is an open access article distributed under the Creative Commons Attribution License, which permits unrestricted use, distribution, and reproduction in any medium, provided the original work is properly cited.

\begin{abstract}
The aim of this article is to provide a preliminary estimate of how much CAM is evidence-based. For this purpose, I calculated the percentage of 685 treatment/condition pairings evaluated in the "Desktop Guide to Complementary and Alternative Medicine" which are supported by sound data. The resulting figure was $7.4 \%$. For a range of reasons, it might be a gross over-estimate. Further investigations into this subject are required to arrive at more representative figures.
\end{abstract}

\section{Introduction}

A lively discussion exists about the question as to how much of conventional medicine might be based on sound evidence [1]. One figure that is often cited is $15 \%$ [2]. It presents, however, unreliable and out-dated information: the figure can be traced back to a small survey conducted in 1960/61 of prescribing practises of family doctors in a northern British town, which looked toward controlling prescribing costs [3]. Other experts have published more convincing data showing that an average of $76 \%$ of interventions are supported by some form of compelling evidence, with an average of $37 \%$ of interventions being supported by randomized clinical trials (RCTs) [3]. A recent systematic review [4] of the topic found that, in general internal medicine, over 50\% [5] and in psychiatry over 65\% [6] of interventions are based on positive data from RCTs.

The discussion about the evidence-base of CAM is far less lively. Here I present a first attempt to generate some data and hopefully a constructive discussion on this potentially important subject.

\section{Methods}

As a basis for my assessment, I used our own book The Desktop Guide to Complementary and Alternative Medicine [6]. In this book, we evaluate the research evidence from clinical trials and systematic reviews as it pertains to any type of CAM for a wide range of conditions $(n=46)$. For each condition, we compiled a "summary of clinical evidence" table in which the treatments are categorized according to the "weight" and "direction" of the evidence. The "weight" is conceptualized as a composite measure of the quantity, quality and level of the research evidence, which refers to the confidence that can be placed on that evidence [6]. The quantity refers to the total patient sample included in all clinical trials - there could, for instance, be five studies with an average of 20 patients resulting in a total sample of 100; this would be less than a single study with a sample of 300 . The quality of the trial evidence refers to the likelihood of bias, usually estimated with a score such as the Jadad score [7]. The level of the evidence refers to the hierarchy of research evidence where systematic reviews are on top and opinion or anecdotal evidence at the bottom. The "direction" of the evidence signals whether the effect is clearly positive, tentatively positive, uncertain, tentatively negative or clearly negative [6]. The book has a full methods section to maximize transparency and reproducibility. It describes our assessments in more detail [6].

For the purpose of this analysis, I have simply counted the number of treatments which obtained the maximum "weight" and also were rated as "clearly positive" in our "summary of clinical evidence" tables. This provided the number of treatments that are supported by good evidence (if one therapy was effective for two indications it was counted twice). Subsequently, this figure was put in relation to the total number of treatment/condition pairings from all the "summary of clinical evidence" tables in our book [6].

\section{Results}

Fifty-one treatments were characterized as having maximum "weight" of evidence as well as being "clearly positive." The total number of treatment/condition pairings was 685 . 
TABLE 1: CAM treatments based on sound evidence.

\begin{tabular}{|c|c|}
\hline Intervention & Conditions \\
\hline Acupuncture & Nausea/vomiting induced by chemotherapy \\
\hline Acupuncture & Osteoarthritis \\
\hline African plum & Benign prostatic hyperplasia \\
\hline Allium vegetables & Cancer prevention \\
\hline Aromatherapy/massage & Cancer palliation \\
\hline Biofeedback & Hypertension \\
\hline Biofeedback & Migraine \\
\hline Chondroitin & Osteoarthritis \\
\hline Co-enzyme Q10 & Hypertension \\
\hline Diet & Rheumatoid arthritis \\
\hline Ephedra sinica & Overweight \\
\hline Exercise & Cancer prevention \\
\hline Exercise & Cancer palliation \\
\hline Exercise & Chronic fatigue syndrome \\
\hline Exercise & Depression \\
\hline Exercise & HIV/AIDS \\
\hline Fiber & Irritable bowel syndrome \\
\hline Ginkgo biloba & Alzheimer's disease \\
\hline Ginkgo biloba & Peripheral vascular disease \\
\hline Glucosamine & Osteoarthritis \\
\hline Green tea & Cancer prevention \\
\hline Group behaviour therapy & Smoking cessation \\
\hline Guar gum & Diabetes \\
\hline Guar gum & Hypercholesterolemia \\
\hline Hawthorn & Chronic heart failure \\
\hline Horse chestnut & Chronic venous insufficiency \\
\hline Hypnotherapy & Labor pain \\
\hline Kava & Anxiety \\
\hline Massage & Anxiety \\
\hline Melatonin & Insomnia \\
\hline Music therapy & Anxiety \\
\hline Oat & Hypercholesterolemia \\
\hline Padma 28 & Peripheral vascular disease \\
\hline Peppermint/caraway & Non-ulcer dyspepsia \\
\hline Phytodolor & Osteoarthritis \\
\hline Phytodolor & Rheumatoid arthritis \\
\hline Psyllium & Constipation \\
\hline Psyllium & Diabetes \\
\hline Red clover & Menopause \\
\hline Relaxation & Anxiety \\
\hline Relaxation & Insomnia \\
\hline Relaxation & Nausea/vomiting induced by chemotherapy \\
\hline$S$-adenosylmethionine & Osteoarthritis \\
\hline Saw palmetto & Benign prostatic hyperplasia \\
\hline Soy & Hypercholesterolemia \\
\hline St John's wort & Depression \\
\hline Stress management & HIV/AIDS \\
\hline Tomato (lycopene) & Cancer prevention \\
\hline Vitamin C & Upper respiratory tract infection (treatment) \\
\hline Water immersion & Labor pain \\
\hline Yohimbine & Erectile dysfunction \\
\hline
\end{tabular}


Consequently, $7.4 \%$ of them were based on sound evidence. Table 1 provides a list of these 51 treatment/condition pairings.

\section{Discussion}

The estimate that $7.4 \%$ of CAM is based on sound evidence may well be over-optimistic. We selected the conditions for inclusion in our book [6] on the basis of two main criteria: first, the condition had to be relevant, that is, commonly seen in primary care or frequently treated with CAM and/or there had to be sufficient trial data to write a chapter. Thus, this evidence summarized in the present article represents a positive selection. Had we chosen different conditions for our book, the percentage would most likely have been lower.

A glance at Table 1 furthermore informs us that several of the included modalities, for example, exercise, group behaviour therapy, stress management, fiber intake or biofeedback, could easily be classified as conventional interventions rather than CAM. Had we excluded them, the percentage of evidence-based CAM would have declined further.

Finally, several cases of "sound" evidence included in Table 1 might need revision in the light of evidence that has emerged since the publication of our book. Examples include saw palmetto (Serenoa repens) [8], glucosamine [9-12], Ginkgo biloba [13-16] and acupuncture which, according to recent findings, may not be more efficacious than sham acupuncture $[17,18]$.

Another concern is that the present analysis merely relates to the question of how many therapies might be supported by sound research evidence. It does not address the question of how solidly CAM practice is evidence-based. This would require an assessment of which treatments are used and how often. Such a research project would be complex but would certainly be a valuable contribution to the literature.

Although my estimate of how much of CAM is evidencebased draws on a critical evaluation of the available evidence, it still presents a rather optimistic view. Further investigations into this subject are required to arrive at more representative figures.

\section{References}

[1] E. Ernst, "How much of general practice is based on evidence?" British Journal of General Practice, vol. 54, no. 501, pp. 316317, 2004.

[2] R. Smith, "Where is the wisdom...the poverty of medical evidence," British Medical Journal, vol. 303, pp. 798-799, 1991.

[3] R. Imrie and D. W. Ramey, "The evidence for evidence-based medicine," Complementary Therapies in Medicine, vol. 8, pp. 123-126, 2000.

[4] P. Matzen, "How evidence-based is medicine? A systematic literature review," Ugeskr Laeger, vol. 165, pp. 1431-1435, 2003 (Danish).

[5] P. Gill, A. C. Dowell, R. D. Neal, N. Smith, P. Heywood, and A. E. Wilson, "Evidence based general practice: a retrospective study of interventions in one training practice," British Medical Journal, vol. 312, pp. 819-821, 1996.
[6] E. Ernst, M. H. Pittler, B. Wider, and K. Boddy, The Desktop Guide to Complementary and Alternative Medicine, Mosby/Elsevier, Edinburgh, UK, 2nd edition, 2006.

[7] A. R. Jadad, R. A. Moore, D. Carroll, C. Jenkinson, D. J. Reynolds, D. J. Gavaghan et al., "Assessing the quality of reports of randomized clinical trials: is blinding necessary?" Controlled Clinical Trials, vol. 17, pp. 1-12, 1996.

[8] S. Bent, C. Kane, K. Shinohara, J. Neuhaus, E. S. Hudes, H. Goldberg et al., "Saw palmetto for benign prostatic hyperplasia," The New England Journal of Medicine, vol. 354, pp. 557-566, 2006.

[9] D. O. Clegg, D. J. Reda, C. L. Harris, M. A. Klein, J. R. O’Dell, M. M. Hooper et al., "Glucosamine, chondroitin sulfate, and the two in combination for painful knee osteoarthritis," The New England Journal of Medicine, vol. 354, pp. 795-808, 2006.

[10] R. M. Rozendaal, B. W. Koes, G. J. van Osch, E. J. Uitterlinden, E. H. Garling, S. P. Willemsen et al., "Effect of glucosamine sulfate on hip osteoarthritis: a randomized trial," Annals of Internal Medicine, vol. 148, pp. 268-277, 2008.

[11] T. Kawasaki, H. Kurosawa, H. Ideda, S. G. Kim, A. Osawa, Y. Takazawa et al., "Additive effects of glucosamine or risedronate for the treatment of osteoarthritis of the knee combined with home exercise: a prospective randomized 18-month trial," Journal of Bone and Mineral Metabolism, vol. 26, pp. 279-287, 2008.

[12] S. P. Messier, S. Mihalko, R. F. Loeser, C. Legault, J. Jolla, J. Pfruender et al., "Glucosamine/chondroitin combined with exercise for the treatment of knee osteoarthritis: a preliminary study," Osteoarthritis and Cartilage, vol. 15, pp. 1256-1266, 2007.

[13] P. Canter and E. Ernst, "Ginkgo biloba is not a smart drug: an updated systematic review of randomized clinical trials testing the nootropic effects of G. biloba extracts in healthy people," Human Psychopharmacology, vol. 22, pp. 265-278, 2007.

[14] H. H. Dodge, T. Zitzelberger, B. S. Oken, D. Howieson, and J. Kaye, "A randomized placebo-controlled trial of Ginkgo biloba for the prevention of cognitive decline," Neurology, vol. 70, no. 19 Pt 2, pp. 1809-1817, 2008.

[15] S. T. DeKosky, J. D. Williamson, A. L. Fitzpatrick, R. A. Kronmal, D. G. Ives, J. A. Saxton et al., "Ginkgo biloba for prevention of dementia: a randomized controlled trial," Journal of the American Medical Association, vol. 300, pp. 2253-2262, 2008.

[16] R. McCarney, P. Fisher, S. Iliffe, R. Van Haselen, M. Griffin, J. van der Meulen et al., "Ginkgo biloba for mild to moderate dementia in a community setting: a pragmatic, randomised, parallel-group, double-blind, placebo-controlled trial," International Journal of Geriatric Psychiatry, vol. 23, pp. 1222-1230, 2008.

[17] E. Ernst, "Acupuncture-a critical analysis," Journal of Internal Medicine, vol. 259, pp. 125-137, 2006.

[18] H. H. Moffet, "Sham acupuncture may be as efficacious as true acupuncture: a systematic review of clinical trials," Journal of Alternative and Complementary Medicine, vol. 15, no. 3, pp. 213-216, 2009. 


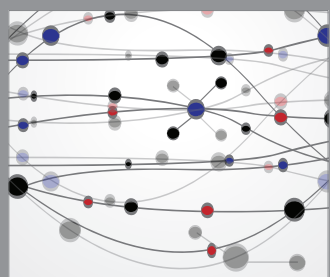

The Scientific World Journal
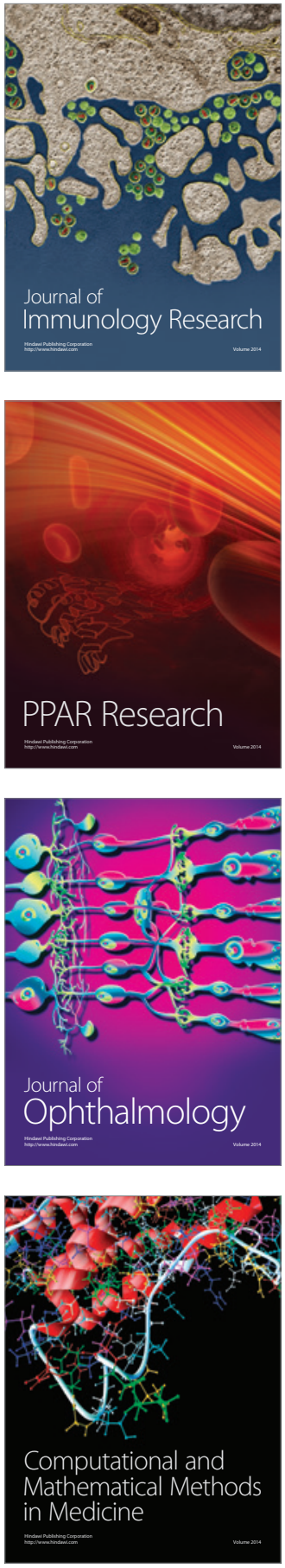

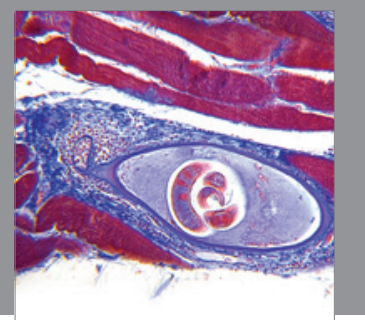

Gastroenterology

Research and Practice
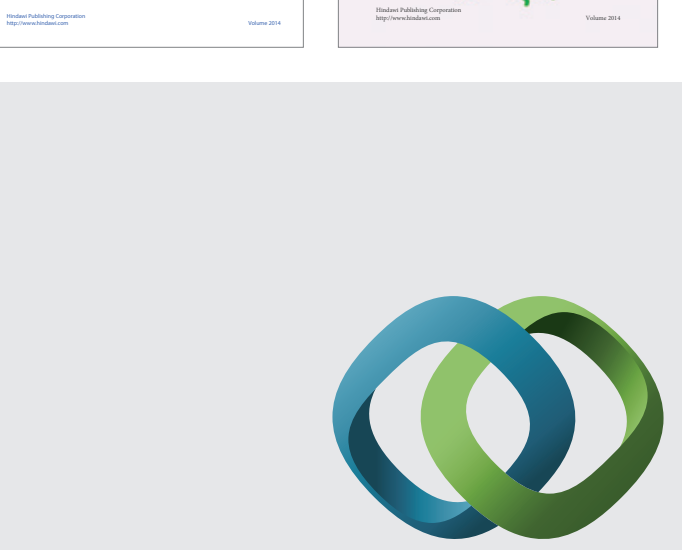

\section{Hindawi}

Submit your manuscripts at

http://www.hindawi.com
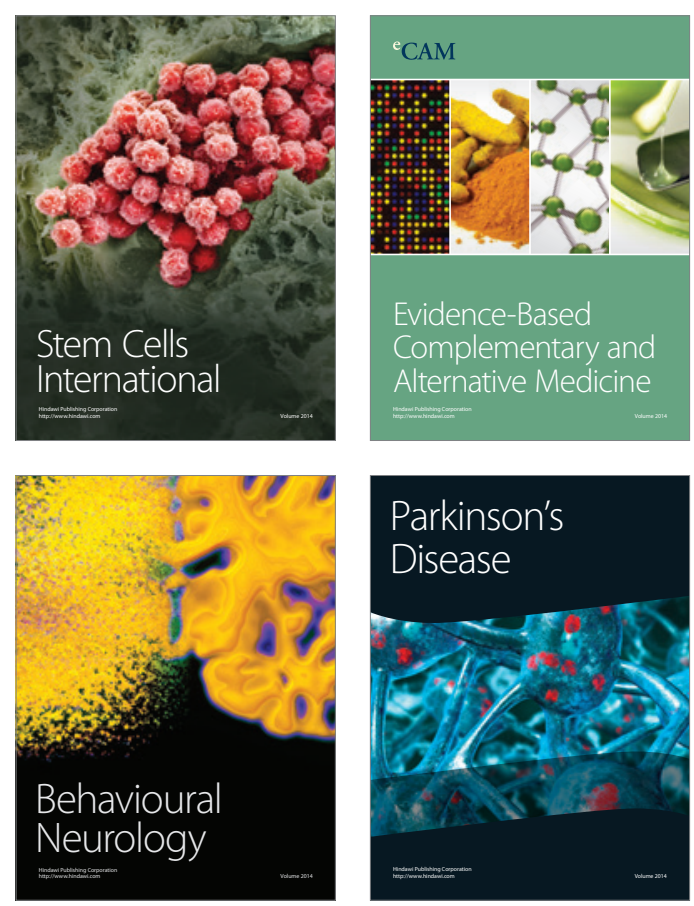

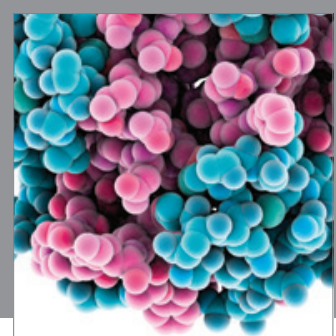

Journal of
Diabetes Research

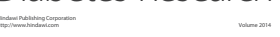

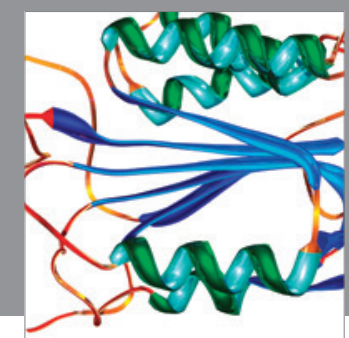

Disease Markers
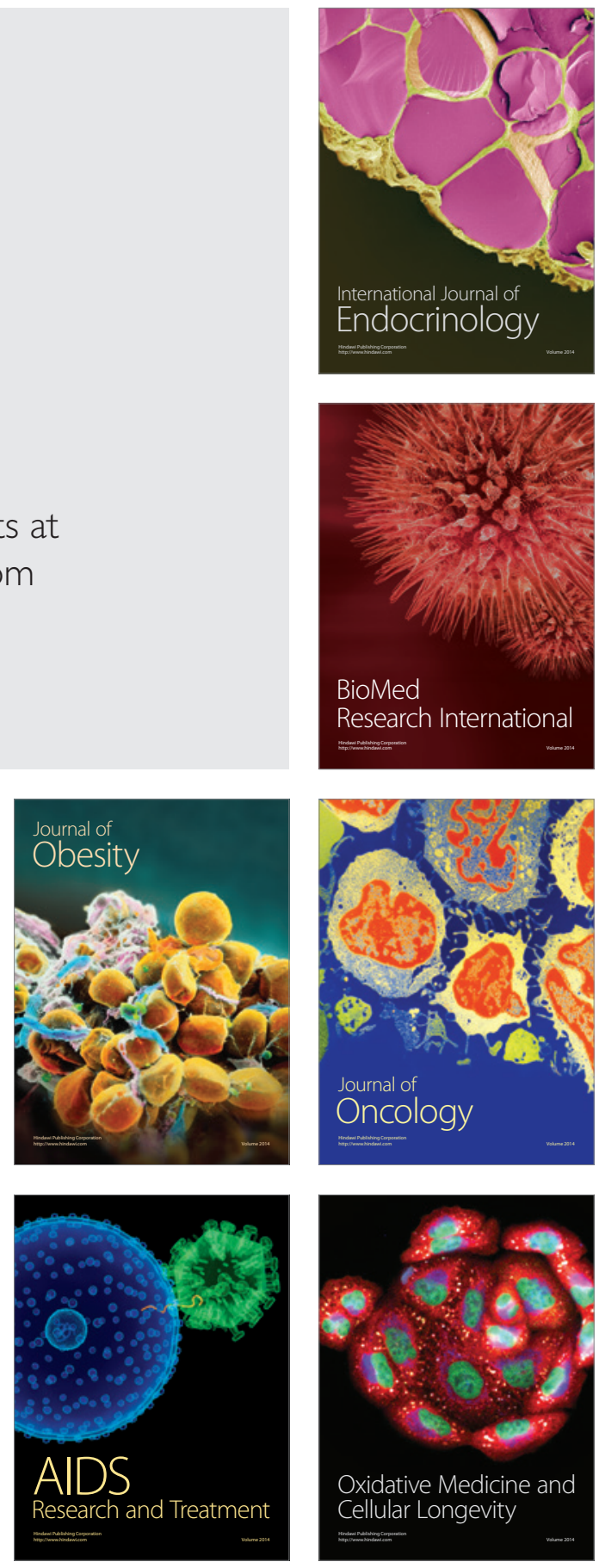